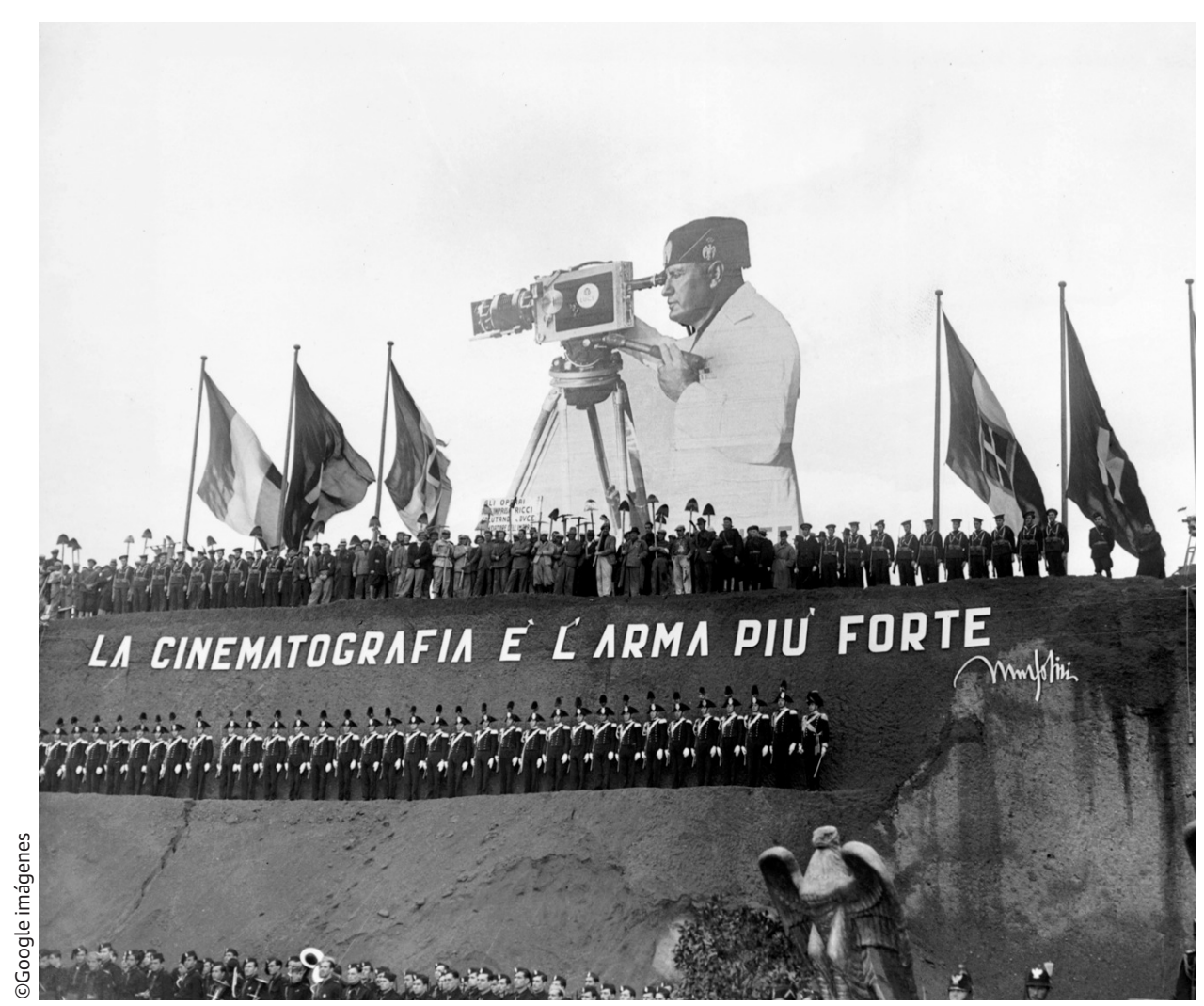

\title{
EL CINE INFORMATIVO: ¿EL ARMA MÁS FUERTE? LA RECEPCIÓN DE LOS NOTICIARIOS CINEMATOGRÁFICOS LUCE DURANTE EL FASCISMO
}

IS THE CINEMATIC NEWSREEL THE STRONGEST WEAPON? THE "LUCE" NEWSREEL RECEPTION DURING FASCISM

Carlota Coronado Ruiz / carlotacoronado@gmail.com UNIVERSIDAD COMPLUTENSE DE MADRID 


\section{RESUMEN}

El noticiario cinematográfico Luce fue uno de los principales instrumentos de propaganda del fascismo. Para Mussolini el cine era el arma más fuerte, sin embargo, la eficacia de la propaganda cinematográfica sobre la población no fue según lo esperado, en especial la del cine de no ficción. Este artículo pretende valorar, a través de testimonios de historia oral, cuál fue la influencia que tuvo el noticiario cinematográfico Luce en la población italiana durante el fascismo: qué grado de veracidad se concedió a la información cinematográfica, qué noticias fueron las más reiteradas, así como qué imagen se ofreció de Italia, de su líder y hasta qué punto influyó en la mentalidad colectiva.

PALABRAS CLAVE Materialismo histórico, teoría crítica, colonialismo, ideología, marxismo, inconsciente político

\section{ABSTRACT}

The Luce newsreel was a fascist-pivotal propaganda instrument. Mussolini thought movies were the strongest weapon; however, the efficiency of cinematographic propaganda on people did not work as well as expected, especially nonfiction. This article intends to value, through oral testimonies, the influence of Luce newsreel on the Italian population during fascism, the degree of truth of film news, and which of those pieces of news were more repeated, as well as the influence of the Italian and its leader image on the collective mind.

KEYWORDS

Nonfiction films, propaganda, newsreels, Italy, fascism

Recibido: 12 de enero de 2016

Aceptado: 7 de mayo de 2016 


\section{INTRODUCCIÓN: OBJETIVOS Y METODOLOGÍA}

Los noticiarios cinematográficos han sido uno de los instrumentos de propaganda considerados más eficaces en el siglo XX: se trataba de un medio de comunicación de masas que llegaba a un gran número de espectadores, tanto analfabetos como no. La capacidad de persuasión de la imagen era, además, mayor que la de la palabra, hablada o escrita. Por otro lado, la veracidad que se concedía a las imágenes permitía una mayor persuasión y que ésta fuera más eficaz. Sin embargo, para establecer cuál fue la influencia real que ejercieron estos mensajes propagandísticos en una determinada audiencia es necesario hacer un estudio de la recepción. Este es el objetivo de este artículo: valorar cuánta fue la influencia del noticiario Luce -noticiario cinematográfico oficial y obligatorio durante fascismo ${ }^{1-}$ en las actitudes y mentalidades colectivas.

En otros países se han llevado a cabo estudios sobre noticiarios cinematográficos ${ }^{2}$ y especialmente sobre noticiarios en los fascismos. Pero la bibliografía existente se centra en el análisis de contenidos, desde el lenguaje cinematográfico utilizado a las temáticas más recurrentes, asî como en el contexto de producción de los noticiarios. Estas obras no ofrecen datos sobre la recepción de los noticiarios entre las audiencias y su influencia ${ }^{3}$, objetivo de este artículo.

Para establecer hasta qué punto la propaganda cinematográfica del régimen de Mussolini fue eficaz entre el público, así cómo qué modelos y estereotipos sociales y de género calaron con más fuerza entre los espectadores, se ha llevado a cabo un estudio de recepción basado en la historia oral. Resulta complicado, sin embargo, establecer cuáles eran los gustos del público en una determinada época o hasta qué punto las modas de la pantalla influían en los espectadores de entonces. Las fuentes tradicionales de investigación como la prensa aportan una información objetiva, pero no suficiente. Así, por ejemplo, los datos de recaudación de taquilla o los anuncios publicitarios de determinadas películas, pueden dar idea de cuáles eran las películas más vistas o las divas más admiradas, pero resultan insuficientes no sólo a la hora de recrear cómo era el espectáculo cinematográfico en una determinada época, sino sobre todo, para establecer el grado de influencia de un mensaje cinematográfico cargado de gran intencionalidad persuasiva como los noticiarios cinematográficos fascistas.

Por su parte, los estudios basados en fuentes orales resultan menos objetivos y presentan limitaciones y ausencias. Pero también, gracias a ellos, es posible conocer aspectos que los periódicos de la época u otras fuentes oficiales no reproducían, como son los hábitos de ir al cine, las formas de asistencia o los gustos de los espectadores. Así pues, a través de este estudio de recepción basado en las fuentes orales se podrán reconstruir los gustos de la audiencia italiana entre 1927, año de creación del noticiario Luce y 1945, final del monopolio cinematográfico de Luce después de la caída del fascismo al final de la Segunda Guerra Mundial. Para ello se han realizado 30 entrevistas a ancianos que nacieron antes y durante el fascismo y que vivieron y fueron al cine entre los años veinte y mediados de los cuarenta.

Para llevar a cabo la selección de la muestra se han tenido en cuenta la bibliografía sobre el cine durante el fascismo ${ }^{4}$, así como estudios sociológicos que analizan las características so-

1 El noticiario Luce fue el primer noticiario cinematográfico de producción italiana. Nació en 1927 y se proyectaba obligatoriamente en todos los cines del país. Con la caída del fascismo, comenzaron las dificultades para Luce y después del 25 de abril de 1945, el noticiario se recicló en las pantallas con el nombre de Nuova Luce. Sin embargo, seguía recordando demasiado al fascismo, por lo que terminaría por desaparecer en 1946 (ARGENTIERI, Mino. L'occhio del regime. Informazione e propaganda nel cinema del fascismo, Vallecchi, Florencia, 1979).

2 Cfr. FIELDING, Raymond. The American Newsreel 1911-1967, Norman, University Oklahoma Press, 1972; HURET, Marcel. Ciné actualités: histoire de la presse filmée, 1895-1980, H. Veyrier, París, 1984; TRANCHE, Rafael R.; SÁNCHEZ-BIOSCA, Vicente y OTERO, José María. NO-DO: el tiempo y la memoria, Cátedra, Madrid, 2000.

3 En MONTERO, Julio y PAZ, María Antonia. Lo que el viento no se llevó: el cine en la memoria de los españoles (1931-1982), Ediciones Rialp, Madrid, 2011, se hace un estudio de los públicos durante el franquismo y se incluyen entrevistas de Historia Oral sobre recepción cinematográfica, pero no se centra en el noticiario NO-DO, sino en el cine en general. 
cio-demográficas de la población italiana en estos años ${ }^{5}$. Según éstos, se trataba de una sociedad prevalentemente rural: después de la Primera Guerra Mundial casi el 70\% de los italianos vivían en el campo. Sin embargo, muchos italianos abandonaron sus pueblos natales para encontrar nuevas oportunidades en la ciudad. Este dato se refleja en la muestra de los entrevistados: aunque la mayor parte de ellos nació en el campo -veinte de treinta, un 66\%-, la mitad de ese total emigró a la ciudad. El 34\% restante tiene procedencia urbana. La mayor parte de ellos han vivido en ciudades pequeñas y medianas de provincias.

Las clases medias y altas italianas eran las que con más frecuencia asistían al cinematógrafo, pero suponen un porcentaje muy pequeño del público total de un espectáculo de masas como el cine. Al definir el perfil del público italiano del período comprendido entre 1928 y 1953 se aprecia que no era ni médico, ni universitario y mucho menos, rico. El espectador de cine de esta época era campesino, pobre, con bajo nivel de estudios.

Así, en la selección de la muestra, se ha intentado recoger la mayor diversidad posible en cuanto a género, situación cultural, social, política y regional, pero siempre teniendo en cuenta el perfil sociocultural del público de la época. Se ha entrevistado a 18 mujeres y 12 hombres, un desequilibrio que se explica por la mayor longevidad de las mujeres. El mayor de los entrevistados nació en 1907 y el menor, en 1932. Hay 25 años de diferencia entre ambos extremos, pero muchas cosas en común: la mayor parte ha vivido la infancia y adolescencia, períodos en los que tenían más tiempo para dedicar a las diversiones y al ocio, durante el fascismo. Su experiencia cinematográfica comienza en el período de entreguerras, pero fue después de la Segunda Guerra Mundial cuando tuvieron un contacto más constante con el cine, sobre todo por la mejora de las circunstancias económicas, políticas y sociales, a partir de entonces.

El 80\% de los entrevistados estudió sólo hasta los 12 ó 13 años, es decir, hasta la Quinta Ele- mentare, y todos aprendieron a leer y escribir. De los treinta entrevistados, sólo ocho estudiaron antes de la consolidación del Régimen fascista ${ }^{6}$. El resto conoció la escuela fascista con todas sus consecuencias: desde el estudio de materias como Cultura fascista a la obligación de pertenecer a los grupos paramilitares a partir de los siete años de edad.

La educación fue un instrumento de propaganda fundamental para el Régimen de Mussolini, no sólo para la transmisión de los dogmas del fascismo, sino también de valores o formas de vida. La generación de los entrevistados fue la primera que nació y vivió su infancia y adolescencia con el fascismo. No conocían lo anterior, por lo que era muy difícil que se opusieran al Régimen. Muchos no entendían todo lo que rodeaba al fascismo, pero seguían la máxima del Duce: Credere, obbedire, combattere. Así, desde el punto de vista político, todos los entrevistados declaran su falta de interés en la política durante sus años de juventud. Fue ya en la Segunda Guerra Mundial, y sobre todo, en la posguerra, cuando manifestaron abiertamente su antifascismo.

El modelo de entrevista que se ha confeccionado no es un cuestionario cerrado dado que un test con respuesta cerrada no permite la valoración cualitativa que se pretende en un estudio de Historia Oral como éste. Aunque para el análisis de resultados se han tenido en cuenta datos cuantitativos que se han traducido en porcentajes, lo que resulta más interesante son las valoraciones que hacen los entrevistados, de las cuales se han extraído para este artículo las más relevantes.

4 Cfr. CARABBA, Claudio. Il cinema del ventennio nero, Vallecchi, Florencia, 1974; REDI, Riccardo. Cinema italiano sotto il fascismo, Marsilio, Venecia, 1979; BRUNETTA, Gian Piero. Historia del cinema italiano. Il cinema del regime (1929-1945), Roma, Editori Riuniti, 2001, entre otros.

5 Cfr. QUAZZA, Guido (ed.). Fascismo e società italiana, G. Einaudi, Turín, 1973.

6 Son los nacidos entre 1907 y 1912 . Empezaron a estudiar con 7 años y terminaron con 12-13, lo que coincidía en algunos casos con los primeros años del régimen. 
Estas treinta entrevistas realizadas a personas de edades comprendidas entre setenta y cuatro y noventa y nueve años ${ }^{7}$, han generado un rico material procedente del recuerdo, y por lo tanto, cargado de subjetividad, pero que ha permitido una cierta reconstrucción de los gustos del público de entonces y saber el nivel de aceptación de los noticiarios cinematográficos entre los espectadores. Así, aunque los resultados de esta investigación puedan ser limitados en algunos aspectos, a través de la Historia Oral se muestra la influencia desde un punto de vista cualitativo de la propaganda cinematográfica fascista.

\section{EL NOTICIARIO "LUCE" ENTRE EL RECUERDO Y EL OLVIDO}

El noticiario Luce fue uno de los medios cinematográficos más importantes utilizado por Mussolini para difundir la propaganda oficial del régimen fascista. Su importancia radica precisamente en eso, en la gran difusión de la que gozaba: por una parte, los noticiarios cinematográficos Luce eran obligatorios en todo el territorio nacional8; por otra, poseía el monopolio de la información audiovisual. En los primeros años del fascismo se produjo el paso hacia la dictadura a través de una serie de leyes que impedían derechos fundamentales como la libertad de expresión. El 10 de julio de 1924 un decreto-ley abolía la libertà di stampa, lo que suponía que los medios de comunicación de masas estaban controlados o dependían del Régimen.

Luce (L'Unione Cinematográfica Educativa) nació en 1924 sobre las estructuras de una pequeña empresa privada, el Sindacato Istruzione Cinematografica, fundada pocos meses antes por el periodista Luciano De Feo, especialista en economía. De Feo se dio cuenta de que en Italia existían las condiciones necesarias para dar vida a una producción sistemática de películas con fines educativos. Para ello, intentó involucrar en el proyecto a jerarcas fascistas, para obtener ayudas económicas. Para el Régimen lo que resultaba interesante del medio cinematográfico no era sólo la función didáctica, sino que podía contribuir a la consolidación del consenso ${ }^{9}$.

En julio de 1925, Mussolini nacionalizó Luce, con el fin de constituirla en el ente estatal para la propaganda, principalmente, para la interior. En 1927 nació uno de los más potentes instrumentos de propaganda de masas: el Giornale Luce. Desde el punto de vista del contenido, el noticiario Luce se caracterizaba por la banalidad de sus noticias. Son lo que se llamaría soft news o noticias blandas: de inauguraciones a folclore, pasando por noticias curiosas o visitas oficiales. En casi todas, siempre se encontraba un motivo que justificara la aparición de Mussolini: visitas del Duce a la industria italiana, inauguraciones de obras públicas o conmemoraciones de días importantes para el Régimen. Subyacía, por tanto, la intención de transmitir una imagen tranquila de un país en armonía social y política.

La influencia que el noticiario cinematográfico podía tener sobre las masas era algo que un periodista como Mussolini podía intuir, sobre todo cuando el índice de analfabetismo entre la población italiana era tan alto en los años veinte. Ante un público sin cultura, un instrumento propagandístico como el cinegiornale Luce ofrecía muchas posibilidades. Hay que tener en cuenta que el cine era ya un espectáculo de masas y que el número de noticiarios Luce aumentaba cada año: en 1927 se produjeron 201.447 metros de

7 Se han llevado a cabo de forma presencial por parte de la autora, y de forma individual con cada uno de los entrevistados/as.

8 "A partir del 1 de enero de 1926 cada uno de los programas cinematográficos deberá comprender la proyección de un Giornale Italiano relativo a los acontecimientos más importantes de carácter patriótico y de propaganda que interesen a Italia". Artículo 4 de la propuesta de ley sobre el cine nacional de 1925, en LAURA, Ernesto G. Le stagioni dell'aquila. Storia dell'Istituto Luce, Ente dello Spettacolo, Roma, 2000, p. 32.

9 El interés del fascismo por los fines educativos del cine, entendidos en realidad como propaganda, se plasmó en el establecimiento en Roma en 1927 de la sede del Instituto Internacional de Cinematografía Educativa, cuya principal tarea consistiría en favorecer la producción, difusión e intercambio entre países de películas educativas (sobre enseñanza, arte, industria, agricultura, etc). HERRERA LEÓN, Fabián. "México y el Instituto Internacional de Cinematografía Educativa, 1927-1937", Estudios de historia moderna y contemporánea de México, Vol. 1, n. 36 (2008), pp.225-226. 
negativo; en el primer semestre de 1929, 797.500 metros $^{10}$. A finales de 1940, se habían puesto en circulación más de diez mil noticiarios Luce ${ }^{11}$.

A pesar de estos datos, si se tiene en cuenta el recuerdo de quienes vieron los noticiarios cinematográficos italianos desde 1927 hasta 1945, la eficacia propagandística de éstos parece ser mínima. Del total de los entrevistados, el 57\% no recuerda en absoluto la existencia de los noticiarios cinematográficos, ni del Luce, ni de sus sucesores en la gran pantalla ${ }^{12}$.

En algunos casos puede considerarse efecto del olvido por la cantidad de años transcurridos. Sin embargo, muchos de los entrevistados recuerdan perfectamente hechos relacionados con el régimen de Mussolini o el cine de aquellos años, y no tienen ningún recuerdo del noticiario Luce. Es posible que el recuerdo sea selectivo y que el desinterés hacia el noticiario haya borrado sus huellas en la memoria de los entrevistados. Algunos han oído hablar del noticiario Luce, pero no recuerdan cómo era: Norma Elmi dice que los discursos del Duce los oía en la radio, pero no recuerda haberlos visto en el cine. Otros, incluso, confunden el noticiario Luce con los cortometrajes cómicos que precedían la proyección del filme en programa: Dina Petracchi afirma que el noticiario Luce eran cómicos que hacían reír. "Me gustaba mucho -señalaba- porque eran muy alegres"13. Es posible que el vago recuerdo de Luce esté relacionado con lo que ahora se considera "políticamente correcto".

De los entrevistados que recuerdan el noticiario Luce -trece personas- sólo a una $-7,6 \%$ de la muestra- le gustaba el noticiario Luce. Para el $23 \%$, era indiferente -la mayor parte lo atribuyen a que eran jóvenes y no les interesaba la política-, y al restante $69,4 \%$ no les gustaba el noticiario del Régimen, es más, lo rechazaban. Este rechazo se debía en algunos casos a razones políticas: lo consideraban propaganda y rechazaban su contenido. "Era un noticiario que estaba al servicio del poder -señala Carlo Ceccherini-. Era más que nada propaganda"14. Pero, en la mayor parte de los casos, lo rechazaban porque les resultaba aburrido: "Para nosotros los jóvenes eran un poco aburridos -afirma Giorgio Fagorziporque era la retórica fascista de siempre, y las noticias económicas no nos interesaban. Cuando ampliaron las noticias, nos gustaba más". Otros, aunque el noticiario tratara de curiosidades o noticias sobre la guerra, preferían dedicar ese tiempo antes del inicio del filme para otros fines: "No me gustaban los noticiarios -señala Lola Beccagli-. Yo, si podía, me besaba con mi novio. Por lo general no nos podíamos besar en el cine, pero si uno quería, iba a las últimas filas, que siempre estaban vacías. El problema era que pasaba siempre el acomodador con la linterna a vigilar"15.

A pesar del rechazo casi unánime del noticiario Luce por parte de los entrevistados, algunos señalan aspectos positivos del mismo. A Giorgio Fagorzi, por ejemplo, le gustaban las noticias sobre la guerra y las conquistas territoriales:

\begin{abstract}
Me gustaba cuando había noticias sobre acciones de guerra, conquistas, escenas bélicas. Me gustaba ver las pruebas de gimnasia anuales. Pero no me gustaba ver a Mussolini con el torso desnudo recolectando el grano, ni tampoco la política. En el fondo, era siempre igual: Mussolini ha inaugurado esto y lo otro. No había debate. Era todo en una única dirección ${ }^{16}$.
\end{abstract}

10 CARDILLO, Massimo. Il duce in moviola : politica e divismo nei cinegiornali e documentari "Luce", Dedalo, Bari, 1983.

11 Para que el noticiario del Régimen llegara a todos los rincones del país, Luce equipó veinticinco autocines y se pusieron en marcha nueve cines ambulantes que, en tres años, realizaron dos mil quinientas proyecciones al aire libre (BERNAGOZZI, Giampaolo. Il mito dell'immagine. L'immagine del mito, Editrice Clueb, Bologna, 1983).

12 Esto contrasta con otros ejemplos de noticiarios cinematográficos en regímenes autoritarios, como el caso del NO-DO en España, de proyección obligatoria durante más de treinta años. Algunos autores señalan la fuerte permanencia del noticiario franquista en la memoria de los españoles: el 74,2\% de los entrevistados en un estudio sobre recepción de cine durante el franquismo reconoce tener un fuerte recuerdo sobre NO-DO (MONTERO, Julio; PAZ, María Antonia. Lo que el viento no se llevó: el cine en la memoria de los españoles (1931-1982), Ediciones Rialp, Madrid, 2011, pp. 112-113).

13 Entrevista a Dina Petracchi (10-07-2014).

14 Entrevista Carlo Ceccherini (03-08-2011).

15 Entrevista Lola Beccagli (23-12-2010). 
A Elia Ducceschi, a quien sí le gustaba el noticiario, le parecía interesante porque "mostraba lo que sucedía en el mundo, las cosas nuevas"17. No le resultaba ni largo, ni aburrido. Aunque se rechazara, el noticiario Luce no se considera largo: "eran cortos y sabrosos"18, dice Soriana Pievaioli. Sin embargo, para muchos, a pesar de su brevedad, eran monótonos y aburridos porque, como señala Giorgio Fagorzi, "el problema era que era siempre igual" 19 .

Ninguno de los entrevistados iba al cine para ver exclusivamente el noticiario cinematográfico: iban a ver la película y el noticiario era simplemente un complemento que no echaban de menos si no lo proyectaban. Casi todos recuerdan que se proyectaban antes de la película: "te los hacían ver a la fuerza antes de la película -se lamentaba Carmela Balboli-. En vez de empezar directamente con la película, te hacían ver el noticiario". Algunos recuerdan, sin embargo, que también se proyectaba en el intermedio, junto a los anuncios de las películas de estreno.

Aunque el noticiario no interesara demasiado, todos los entrevistados permanecían en la sala. Los motivos son distintos: desde el miedo ante un comportamiento poco fascista, al querer aprovechar la oscuridad de la sala en las filas del fondo. "Normalmente -señala Giorgio Fagorzilo veíamos todos: ya que habías pagado... Al fin y al cabo era información". Además, "si salías de la sala -dice Giovanna Luconi- te podías ganar una bofetada de algún radical. Yo me quedaba allí callada"20. Quien salía, como señala Soriana Pievaioli, lo hacía sin ser descubierto.

$\mathrm{Ni}$ en la platea, ni en el gallinero se oían silbidos o abucheos. Tampoco aplausos ni vítores. Por lo general, como señalan todos los entrevistados, la gente estaba callada para evitar problemas. "No se podía gritar contra el noticiario Luce -afirma Lola Beccagli-. Había miedo"21. Así que, "se escuchaba, se estaba callado, y se rechazaba porque venía del fascismo, pero no se podía gritar en voz alta", reconoce Soriana Pievaioli. Pero, aunque no hubiera un rechazo visible, algunos como Carlo Ceccherini recuerdan que "se escuchaba un murmullo en la platea porque había personas que no estaban de acuerdo con lo que veían, pero no lo manifestaban abiertamente. Había sólo un poco de murmullo"23.

Las noticias con las que no estaban de acuerdo quienes murmuraban eran las que mostraban una Italia imperial, uniformada, fascista y con un único líder, el Duce. Todos reconocen que el noticiario Luce era un monográfico sobre Mussolini. En la memoria de todos está el Duce con el torso desnudo y la azada en mano para hacer propaganda de la celebérrima Batalla del grano. "Mostraban al Duce que sembraba el trigo, el $\mathrm{Du}$ ce que recolectaba el trigo, el Duce que saludaba a la gente, el Duce que comía, todo Duce, Duce, Duce"24, afirma Lola Beccagli.

Además de la propaganda personalista, el público de entonces recuerda las noticias sobre la potencia militar italiana y sobre el Imperio.

\section{Mostraban sólo las victorias, los avances de nuestras tropas, la demostración de que Italia vencía siempre, que no perdía nunca. Nos enseñaban el armamento. Después pudimos comprobar, por nosotros mismos, que nuestras armas eran escasas. Había noticias so- bre política, sobre deporte. En tiempo de guerra, nos mostraban la guerra en el norte de África, el ejército italiano y los camisas negras. Para el noticiario gana- ban siempre ellos 25 .}

La guerra es uno de los temas más recordados por todos los entrevistados, desde la guerra de Etiopía hasta la Segunda Guerra Mundial26. "Noticias pocas: sólo se hablaba de la guerra de Áfri-

\footnotetext{
16 Entrevista Entrevista a Giorgio Fagorzi (23-07-2006).

17 Entrevista a Elia Ducceschi (19-12-2010).

18 Entrevista a Soriana Pievaioli (02-08-2015).

19 Entrevista a Giorgio Fagorzi (23-07-2006).

20 Entrevista a Giovanna Luconi (23-07-2010).

21 Entrevista Lola Beccagli (23-12-2010).

22 Entrevista a Soriana Pievaioli (02-08-2015).

23 Entrevista Carlo Ceccherini (03-08-2011).

24 Entrevista Lola Beccagli (23-12-2010).

25 Entrevista Carlo Ceccherini (03-08-2011).
} 
ca y del Imperio. Se censuraba todo"27, afirma Loris Romei.

Antes de la guerra, las noticias eran distintas. Así lo señala Giorgio Fagorzi: "el tipo de noticia dependía de cada época. Antes de la guerra todo eran inauguraciones y encuentros con ministros de otros países. También había mucho deporte"28. Los acontecimientos y, sobre todo, las pruebas gimnásticas ejecutadas por los miembros de las organizaciones fascistas están en el recuerdo de todos los entrevistados. Balilla y Piccole Italiane $^{29}$ eran grandes protagonistas del noticiario fascista.

Todos coinciden en que a través del noticiario Luce se hacía propaganda de los aspectos positivos del Régimen ${ }^{30}$ : el progreso económico, el Imperio, las iniciativas del gobierno a favor del pueblo. El noticiario Luce era "Mussolini, el Imperio, las manifestaciones públicas a favor del Régimen, todo propaganda para adiestrar"31. Además de las obras públicas y el progreso, algunos recuerdan otro tipo de iniciativas como los premios a las madres prolíficas.

La mayor parte de las noticias eran publicidad de la dictadura. Mostraban las cosas buenas del fascismo: Mussolini que daba los premios por tener hijos. Querían muchos hijos para luego mandarlos a morir. La propaganda del Régimen no faltaba nunca. Me acuerdo de la propaganda sobre las sanciones: era necesaria porque si no, ¿cómo justificaba Mussolini todo lo que pedía como las alianzas a las esposas? ${ }^{32}$

Después de ver el folclore nacional y las curiosidades internacionales, se continuaba con el programa cinematográfico. A la salida del cine, las escenas de bailes tradicionales o los premios a las madres prolíficas, se habían diluido. El público recordaba y comentaba la película, no el noticiario. En el caso de Luce se debía, como ya se ha señalado, al miedo. Aunque no estuvieran de acuerdo con los contenidos o quisieran hacer algún comentario en público, preferían callar porque era peligroso. En todo caso, "se podían comentar entre los amigos -señala Loris Romei-, pero no te podían oír los demás"33. Algunos, co- mo Elia Ducceschi, expresaban su opinión, pero sólo a su marido, y sin ser escuchados por nadie: "no se lo decía a los demás. Sólo a mi marido. Cuando había propaganda había que tener cuidado porque te podían dar una paliza"34.

Otros no comentaban ni expresaban su opinión, porque les resultaba indiferente, sobre todo, entre los más jóvenes. Sin embargo, algunos de los entrevistados hacían esfuerzos por no expresar el malestar que sentían al ver algunas noticias: "no podías expresar tu malestar -señala Lola Beccagli-. La gente que estaba alrededor, en el cine, parecía tranquila. Nadie podía decir nada. Sin embargo, era muy molesto ver toda esa riqueza, esa elegancia, pero nadie podía decir nada porque si no, te llevaban a comisaría" 35 .

La indiferencia y el rechazo que los entrevistados sentían, les impedía ver las cosas útiles

26 La movilización de los medios de comunicación italianos en la Guerra de Etiopía fue enorme: tanto la prensa el mito de la empresa imperial. En la radio, por ejemplo, se creó el programa diario "Cronache del regime", en el que se informaba puntualmente de los avances italianos en la guerra (TRANFAGLIA, Nicola; MURIALDI, Paolo; LEGNANI, Massimo. La stampa italiana nell'età fascista. Editori Laterza, 1980).

27 Entrevista a Loris Romei (23-12-2014).

28 Entrevista a Giorgio Fagorzi (23-07-2006).

29 La Opera Nazionale Balilla (OBN) fue creada en 1926 como organización cuyo objetivo era dirigir y controlar la educación física y moral de la juventud italiana. Dentro de los cuerpos masculinos se encontraban los Balilla - niños entre 9 y 10 años - y las Piccole Italiane - niñas entre 9 y 13 años (DITTRICH-JOHANSEN, Helga. Le militi dell'idea. Storia delle organizacioni femminili del PNF, L. S. Olschki, Florencia, 2002).

30 Esta intención coincide plenamente con los objetivos de la prensa durante el fascismo. Desde el Ufficio Stampa se controlaba los contenidos de las noticias con el objetivo de eliminar o "minimizar" los aspectos negativos del Régimen, así como exaltar y edulcorar. Así, se redujo al mínimo la crónica negra, por consigna gubernamental, y se contaminó la información con la propaganda fascista: se mitificó la figura del Duce y se potenciaron las noticias sobre el progreso y la modernización del país (CANNISTRARO, Philip V. La fabbrica del consenso: fascismo e mass media. Laterza, 1975 y TRANFAGLIA, Nicola; MURIALDI, Paolo; LEGNANI, Massimo. La stampa italiana nell'età fascista. Editori Laterza, 1980).

31 Entrevista a Soriana Pievaioli (02-08-2015).

32 Entrevista a Sestilio Corpaccioli (08-12-2009).

33 Entrevista a Loris Romei (23-12-2014).

34 Entrevista a Elia Ducceschi (19-12-2010).

35 Entrevista a Lola Beccagli (23-12-2010). 
que se podían aprender con el noticiario. Para la mayoría, no se aprendía nada con el noticiario Luce: era propaganda de la dictadura y "¿la dictadura qué puede enseñarlos?”36, se pregunta Soriana Pievaioli.

\section{LA IMAGEN DE ITALIA EN "LUCE": MARCHAS Y MOSQUETONES}

De las noticias de Luce que son todo "marchas y mosquetones" 37 -como afirma Lidia Borgioli-, la idea que se extraía de Italia era la de una país fascista, fuerte militarmente, imperial. Ésta es la imagen que el noticiario pretendía difundir: una imagen positiva del país. "La Italia que se veía señala Agnese Cuttazzi- era una Italia fascista. Tendían a mostrar una Italia más bella de lo que era: que estábamos todos bien, todos felices"38.

La potencia militar del país es uno de los aspectos que más ha permanecido en el recuerdo de los entrevistados: era una Italia vencedora. "La idea que te transmitían -afirma Soriana Pievaioli- es que era una Italia potente. Te decían que tenía cien mil tanques y te mostraban imágenes con doscientos tanques que pasaban varias veces para parecer más. Se decía continuamente:

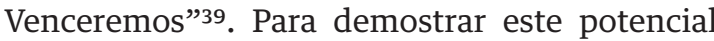
militar se realizaban noticias sobre las fábricas de armamento y se multiplicaban los eslóganes militaristas como Patria e moschetto", "Credere, obbedire e combattere" o "Vinceremo".

Además de potente, la Italia del noticiario $\mathrm{Lu}$ ce era fascista. "Sólo se veían fascistas -recuerda Gina Marradi-. No había otra cosa. Se veía sólo fascistas que estaban bien. Nosotros éramos los que estábamos mal"40. Estos fascistas que presentaba el noticiario del Régimen eran siempre grandes benefactores: "mostraban que el Régimen ayudaba siempre a los más pobres, a los campesinos, daban libretas de ahorro a los más necesitados"41.

"Era una imagen patriótica del país"42 -señala Alda Corsini-. La intención era mostrar a los italianos y al mundo, que Italia era un imperio, como lo había sido en tiempos de los romanos. "Me acuerdo como si fuera ayer: 'las tropas ita- lianas están entrando en Addis Abeba, el enemigo escapa'. Nosotros, los chiquillos, nos los creíamos, tal vez nuestros padres no tanto"43.

Aunque algunos fueran jóvenes en los años de Luce, todos reconocen que no se creían demasiado la propaganda del Imperio. "Del Imperio -reconoce Giorgio Fagorzi-, me gustaba la puesta en escena de los militares, la escenografía con todos uniformados antes de partir, pero luego me daba la risa porque el rey emperador me parecía ridículo" 44 .

La mayoría no creía en el Imperio, porque la situación en la que vivían era muy distinta a la de una Italia imperial y próspera. Todos, y sobre todo sus familias, vivieron con tristeza la gloriosa Giornata della fede: las madres de los entrevistados se vieron obligadas a donar sus alianzas nupciales. "Mi madre se opuso -recuerda Alda Corsini-. No quería dar su alianza, pero como era imposible no hacerlo, tuvo que ir a una anciana y comprarle un anillo peor y dio ése. Todos eran contrarios, pero debían donar la alianza". Lo mismo señala Giovanna Luconi: "mi madre donó la alianza, las rejas de casa, una olla de cobre. Pero no era espontáneo. Decían que era necesario hacerlo. Pasaban por las casas para coger las cosas" 45 .

Todos debían participar en la vida pública del Régimen, aunque no estuvieran de acuerdo. "En las familias fascistas -recuerda Bruno Malentacchi- la Giornata della fede se vivía con entusiasmo, pero en las familias normales no gustaba tanto"46. Lo mismo ocurría con las pruebas de-

36 Entrevista a Soriana Pievaioli (02-08-2015).

37 Entrevista a Lidia Borgioli (05-07-2009).

38 Entrevista a Agnese Cuttazzi (28-12-2010).

39 Entrevista a Soriana Pievaioli (02-08-2015).

40 Entrevista a Gina Marradi (30-07-2014).

41 Entrevista a Giuliana Micheloni (04-11-2010).

42 Entrevista a Alda Corsini (27-10-2010).

43 Entrevista a Bruno Malentacchi (20-12-2009).

44 Entrevista a Giorgio Fagorzi (23-07-2006).

45 Entrevista a Giovanna Luconi (23-07-2010). 
portivas o las marchas de los sábados fascistas. Los niños debían ser Balilla y las niñas Piccole Italiane y debían marchar a paso marcial por el centro de la ciudad. Los padres debían ir a aplaudir, porque si no, se buscaban problemas con los fascistas locales.

Para los entrevistados la imagen que el noticiario difundía de este tipo de manifestaciones públicas correspondía bastante a la realidad. Había propaganda y censura, pero el noticiario mostraba la puesta en escena de las marchas y los desfiles. Esto no quiere decir que Luce fuera fiel a la realidad. La imagen que ofrecían de la vida pública del Régimen recogía toda la parafernalia. Sin embargo, era una realidad sesgada, además de exagerada. Detrás de la escenografĩa existía una Italia con menos fastos.

La Italia en la que vivían los entrevistados era muy distinta a la que pretendía difundir el noticiario Luce. Sin embargo, según algunos entrevistados, esa Italia pobre y atrasada, se dejaba entrever en algunos noticiarios. "La imagen que yo veía de Italia era la de una Italia rural. A veces se veía la inauguración de algún establecimiento industrial, pero la mayor parte de las veces se veía el campo, pueblecitos, una Italia mísera”47.

En la Italia fastuosa y potente que presenta el noticiario Luce, el hombre era el protagonista. Poco espacio había para las mujeres. Así lo recuerdan la mayor parte de los entrevistados: "no había casi mujeres -afirma Alda Corsini-. Siempre hombres. Sólo en los desfiles había algunas mujeres en uniforme" 48 . Las mujeres fascistas con sus uniformes, sus marchas y sus pruebas gimnásticas es uno de los tipos de mujeres presentes en Luce, más recordados por los entrevistados ${ }^{49}$

En Luce estaban las mujeres vestidas de uniforme, las niñas de las colonias, de los campos helioterapéuticos, los de las curas de sol. También las maestras en uniforme, exaltadas. Eran un poco mujeres-soldado. Se veían muchos niños, en las épocas de las colonias, de los premios de natalidad. Recuerdo a las madres prolíficas de Italia. También había actrices, si se estaba rodando un filme en Roma, por ejemplo. ${ }^{50}$
Entre las mujeres presentes en Luce más recordadas por los entrevistados se encuentran las madres prolíficas ${ }^{51}$. De los doce entrevistados que recuerdan la presencia de la mujer en los noticiarios Luce, diez mencionan a las madres de familias numerosas. Recuerdan los premios que les concedía el fascismo y los homenajes públicos que se les dedicaba. Ninguna de ellas reconoce que este tipo de propaganda demográfica le influyera en su decisión en tener más hijos. "Yo he tenido sólo una hija -dice Lola Beccagli- Yo no tenía demasiadas ganas de tener hijos en la situación en la que vivíamos. Además, las madres prolíficas luego no eran reconocidas en la vida cotidiana como heroínas" 52 .

Los entrevistados veían a estas mujeres como instrumento de propaganda. "La madre campesina -señala Giorgio Fagorzi- era usada siempre para fines propagandísticos: las madres tienen que tener hijos para el imperio y por ello deben ser respetadas. Se las mostraba en el noticiario, aunque luego no contaban para nada"53.

\footnotetext{
46 Entrevista a Bruno Malentacchi (20-12-2009).

47 Entrevista a Giorgio Fagorzi (23-07-2006).

48 Entrevista a Alda Corsini (27-10-2010).

49 Este modelo que quedó en el recuerdo del público coincide con una de las imágenes más difundidas de la mujer en la propaganda fascista, como se puede comprobar en numerosos estudios (Cfr. CORONADO RUIZ, Carlota. "Mujeres en uniforme: las organizaciones fascistas femeninas en los noticiarios cinematográficos Luce (1928-1943)", Feminismos, Vol. 1, n. 16 (2010), pp. 181-206; DITTRICH-JOHANSEN, Helga. Le militi dell'idea: storia delle organizzazioni femminili del Partito nazionale fascista. Florence: Leo S. Olschki, 2002, etc.).
}

50 Entrevista a Lola Beccagli (23-12-2010).

51 La esposa y madre ejemplar se convirtió en el estereotipo femenino más repetido en la propaganda fascista. Desde los discursos hasta la prensa, la radio o el cine, presentaban a la madre prolífica y campesina como el modelo ideal de mujer (Cfr. CORONADO, Carlota. "Esposa y madre ejemplar: la maternidad en los noticiarios Luce durante el fascismo (1928-1945)", Historia y comunicación social, vol. 13 (2008), pp. 5-31; DE GRAZIA Vittoria. Le donne nel regime fascista, Marsilio Editori, Venezia, 1993; MELDINI, Piero. Sposa e madre esemplare. Ideologia e politica della famiglia durante il fascismo, Guaraldi Editore, Rimini-Florencia, 1975; MESSINA, Nunzia. Le donne del fascismo. Massaie rurali e dive del cinema nel Ventennio, Ellemme, Roma, 1987, entre otros).

52 Entrevista a Lola Beccagli (23-12-2010). 
Además de las madres prolíficas, los entrevistados recuerdan otro tipo de mujer: las mujeres de los fascistas que iban a los eventos sociales, a las carreras de caballos, las modelos de los desfiles, o las atletas o deportistas. Pocos nombres propios entre éstas. Sólo un entrevistado, Loris Romei, recuerda a Ondina Valli, una campeona olímpica de atletismo a la que el noticiario le dedicó algún número. Las dos mujeres más recordadas por los entrevistados son Rachele Mussolini y la Reina.

El tipo de noticias y de personajes protagonistas del noticiario hacían que éste fuera percibido por los entrevistados como pura propaganda. Para la mayoría, Luce no reflejaba fielmente la realidad, eran mentiras de la dictadura, realidades maquilladas o exageradas. "No era la realidad lo que se veía en Luce -afirma Lola Beccagli. En la realidad había mucha miseria, represión y falta de libertad. Uno no podía siquiera decir que estaba en paro, aunque fuera cierto. Se podía decir "mondo ladro", pero no "governo ladro". Uno no se podía meter con el gobierno" 54 .

De los trece entrevistados que recuerdan el noticiario, ocho ponían en duda los contenidos del noticiario Luce, consideraban que no era verdad. La razón es, en casi todos los casos, la misma: es información procedente del fascismo. Como señala Agnese Cuttazzi, "no me lo creía porque venía del fascio. Además, cuando volvía del cine veía la miseria que teníamos en casa"55. Algunos reconocen que eran indiferentes, que no se planteaban siquiera la posibilidad de ponerlo en duda, porque se habían acostumbrado a ese tipo de propaganda y la aceptaban. "No es que no nos creyéramos lo que decía Luce, simplemente nos habíamos acostumbrado a vivir de esa manera, con una única información, sin poder confrontar. Se aceptaba lo que nos decían. Nos habíamos acostumbrado a estar siempre callados, a no responder, a decir siempre que sí y basta" 56 .

Todos coinciden en que no existían otros medios de comunicación alternativos. "Había prensa clandestina -señala Soriana Pievaioli- pero te buscabas problemas si te descubrían". Durante la Segunda Guerra Mundial, todos señalan Radio
Londra Indipendente como fuente de información libre y veraz. Pero no todos la escuchaban porque, si eran descubiertos, podían terminar en la cárcel.

Al no tener otra fuente de información alternativa durante los veinte años de Régimen, la mayor parte de los italianos, como señalan los entrevistados, se acostumbraba a la propaganda del fascismo y terminaba por aceptarla como información. Algunos de los entrevistados, como Elia Ducceschi, reconocen que se creían lo que decía Luce: "yo pensaba que era verdad" 57 -afirma la señora Ducceschi. "El 90\% de las personas se lo creían ciegamente -señala Giorgio Fagorzi-. También porque el Régimen, algunas cosas positivas, sobre todo en la Italia rural, las había hecho" 58 . Otros entrevistados no se planteaban la veracidad del noticiario, porque eran demasiado jóvenes, o bien porque no les interesaba. Eran sus padres quienes más ponían en duda los contenidos de las informaciones cinematográficas del Régimen. "Más bien era mi madre, que era contraria al Régimen la que no se lo creía afirma Carlo Ceccherini-. Mi padre tenía un poco más de miedo. Yo era un chiquillo. Cuando he crecido, he entendido todas esas cosas y las he rechazado" 59 .

Algunos de los entrevistados reconocen que no prestaban demasiado interés al noticiario $\mathrm{Lu}$ ce. Para Bruno Malentacchi, por ejemplo, "era un pasatiempo, noticias a las que no daba demasiada importancia"60. Esta falta de interés hace que no recuerden con precisión si hubo un rechazo del noticiario Luce con la caída del fascismo. El intento del Istituto Luce de lavar la cara al noticiario con una nueva edición, Nuova Luce, ha pasado al olvido. El recuerdo más nítido que tienen

\footnotetext{
53 Entrevista a Giorgio Fagorzi (23-07-2006).

54 Entrevista a Lola Beccagli (23-12-2010).

55 Entrevista a Agnese Cuttazzi (08-11-2010).

56 Entrevista a Gina Marradi (30-07-2014).

57 Entrevista a Elia Ducceschi (19-12-2010).

58 Entrevista a Giorgio Fagorzi (23-07-2006).

59 Entrevista Carlo Ceccherini (03-08-2011).

60 Entrevista a Bruno Malentacchi (20-12-2009).
} 
es del noticiario Luce, y después de éste tienen una leve impresión de lo que era la Settimana Incom, el noticiario de mayo éxito durante la democracia y hasta la llegada de la televisión.

\section{CONCLUSIONES: ¿ES EL CINE EL ARMA MÁS FUERTE?}

Entre 1930 y 1931 el cine en Italia perdió seis millones de liras de ingresos. Cerraron 350 salas en toda la península. Los espectadores se quedaban en sus casas o iban a divertirse al baile que era más barato. Quienes iban al cine, preferían ver una película americana. Esta crisis económica afectó de manera particular al cine italiano, que no podía competir con el gran gigante americano.

En ayuda del cine nacional, y fundamentalmente por motivos propagandísticos, el gobierno de Mussolini decidió imponer una serie de limitaciones a la distribución del cine americano en las salas italianas. De este modo se pretendía impulsar el cine de producción nacional: era obligatorio programar una película italiana por cada tres extranjeras en los cines de las ciudades de más de 50.000 habitantes. Se estableció además una tasa de importación sobre las películas extranjeras. Después de esta ley de monopolio, el número de películas americanas disminuyó. Las películas inglesas o francesas desaparecieron de la cartelera italiana. Entre 1936 y 1940, el incremento del público en las salas cinematográficas se multiplicó por dos ${ }^{61}$. La mayoría iba a ver películas italianas, pero no porque le gustaran más, sino porque se prohibían las americanas.

Estos datos ponen de manifiesto el interés del Régimen por impulsar el cine nacional y, con él, la propaganda a través del medio de comunicación de masas más eficaz y difundido. Pero, ¿hasta qué punto funcionó esta estrategia propagandística? ¿Cuánto influyó el cine fascista en la población de la época?

Por lo que se deduce de las contestaciones de los entrevistados, la respuesta es bastante clara: la propaganda cinematográfica del Régimen tuvo escasos resultados ${ }^{62}$. En primer lugar, la gente iba poco al cine. Cuando el público no asiste con frecuencia al cine, sólo una vez cada año, poca huella puede dejar entre los espectadores la propaganda del Régimen. Esto se demuestra con el hecho de que sólo la mitad de los entrevistados recuerda el noticiario cinematográfico Luce, de obligada proyección en todas las salas de cine desde 1927. Pocos son, entre los que lo recuerdan, quienes tienen una idea nítida de los temas que se trataban: la mayoría dice que trataban sobre la dictadura, que siempre aparecía Mussolini. Casi no prestaban atención o les resultaba indiferente. Hay que tener en cuenta también que los entrevistados no se consideran fascistas, por lo que es difícil que la propaganda haya dejado demasiada huella en ellos. Además, han pasado muchos años y el recuerdo sobre la eficacia de la propaganda se diluye.

No sólo es baja la asistencia a los cines, también se constata el escaso número de salas. En la mayor parte de los pueblos del Sur de Italia no existían, en los años treinta, salas estables de cine. El gobierno, a través del Istituto Luce y de otras organizaciones, puso en marcha los citados cinemobili.

Pocos cines y poco dinero para gastar en el espectáculo cinematográfico. El Régimen, además, tenía que enfrentarse al gusto del público. La mayoría prefería ver cine americano, el gran enemigo del Régimen, en parte porque mostraba una serie de valores y modelos sociales contrarios a los que pretendía imponer el fascismo63: en el cine americano la vida se representaba como gozo y no como sacrificio; y la mujer como diosa del placer y no como reina de la casa ${ }^{64}$. El cine fascista, sin embargo, debía favorecer la salud fí-

61 ZAGARRIO, Vito. Cinema e fascismo. Film, modelli, immaginari, Marsilio, Venecia, 2004.

62 Esto coincide con la visión del cine fascista de Brunetta, en varios de sus estudios sobre este tema: cfr. BRUNETTA, Gian Piero. Cinema italiano tra le due guerre, Mursia, Milán, 1975; BRUNETTA, Gian Piero. La cinepresa e la storia: fascismo, antifascismo, guerra e resistenza nel cinema italiano. Bruno Mondadori, Milán, 1985.

63 BRUNETTA, Gian Piero. "La lunga marcia del cinema americano in Italia tra fascismo e guerra fredda", ELLWOOD y BRUNETTA (Eds.), Hollywood in Europa, Einaudi, Bolonia, 1988, pp. 37-38. 
sica y moral de la familia, el retorno a la simple vida rural y la eliminación de la lucha de clases.

Las campañas propagandísticas que el Régimen activó a través del cine fueron un fracaso. Los entrevistados bromean sobre ese tipo de propaganda: “¿Quién se creía que Italia era un Imperio?" afirman todos entre risas. La propaganda cinematográfica directa les parece ridícula y es rechazada. Todos los entrevistados reconocen que no se creían nada de lo que aparecía en la pantalla después de las letras de $\mathrm{Lu}$ $c e^{65}$. Sin embargo, entre las películas preferidas de algunos que decían rechazar todo lo que olía a propaganda, hay grandes éxitos del cine propagandístico del Régimen, como Ettore Fieramosca (Alessandro Blasetti, 1938), donde se muestra el valor de los italianos, las características esenciales de la raza y la fuerza del pueblo italiano.

Así se puede llegar a esta conclusión: la propaganda más sutil, en forma de ficción, era aceptada. Lo que molestaba al público era ser conscientes de que algo era propaganda, de ahí que las formas directas como el noticiario Luce fueran rechazadas.

El rechazo de los espectadores era silencioso. Nadie comentaba abiertamente el contenido de los noticiarios para criticarlos. En esto coinciden todos: en aquellos tiempos era mejor estar callados, porque si no, uno se podía buscar problemas con los fascistas del pueblo. Nadie hacía burla del noticiario o del Régimen, ni siquiera en la oscuridad de la sala de cine. Podía ser un problema cuando se encendían las luces.

Este rechazo unánime de la propaganda del Régimen puede ser fruto del paso del tiempo: no se pone en duda, simplemente, después de tantos años y de nueva información, los espectadores de entonces, que tal vez creían a pies juntillas lo que el Régimen les decía, afirman que tampoco en aquella época se creían las cosas que el fascismo les decía.

De ser así, se deduce que el cine no era, al contrario de lo que Mussolini creía, ese arma tan fuerte, puesto que otros métodos propagandísticos como la educación resultaban más eficaces que el cine. La difusión de las ideas del fascismo se consiguió gracias a la labor conjunta de diversos medios: prensa, educación, cine, radio, literatura. Si la propaganda fascista funcionó entre una amplia mayoría de la población, se debe a que educó a varias generaciones en los nuevos valores del Régimen. Niños y jóvenes que no conocían otra cosa que no fuera el fascismo, fueron educados para creer, obedecer y combatir. Como señala uno de los entrevistados, Loris Romei, "el fascismo dio dignidad al pueblo italiano, sobre todo a los jóvenes. Les dio algo en lo que creer"66. Y esto lo consiguió, sobre todo gracias a la educación y a la propaganda. Tal vez el cine no fuera el arma más fuerte, pero consciente o inconscientemente, el pueblo italiano se creía esas ansias de grandeza que Mussolini alimentaba.

Para que esta propaganda funcionara era necesario que hubiera un auditorio, un público asiduo al que repetir una y otra vez las mismas consignas. Y esta asiduidad se daba bastante poco, sobre todo por falta de dinero. El cine no era algo imprescindible. Se trataba de un lujo, una mera diversión, que, en seguida, se vio substituido por otro medio: la televisión. El 90\% de los entrevistados reconoce haber casi dejado de ir al cine después de comprar la televisión.

La cinefilia es un fenómeno de los años sesenta que han vivido sus hijos y nietos, pero que no se entiende en la generación de los entrevistados. Antes de la televisión iban al cine, porque no había otra diversión, no porque realmente sintieran pasión por él. Además, en muchas ocasiones no les importaba la película que iban a ver, sino el hecho de ir al cine. No es una experiencia personal, sino más bien un evento social. No es la película la que mueve a ir al cine, sino la gente con la que se va.

En 1933 Leo Longanesi escribe en la revista Film Italiano que "el noticiario Luce aburre y no

64 MESSINA, Nunzia. Le donne del fascismo. Massaie rurali e dive del cinema nel Ventennio, Ellemme, Roma, 1987, p. 26.

65 Hay que tener en cuenta que esta afirmación se hace después de más de setenta años. Es posible que en su momento se creyeran esa información y no reconocieran toda la propaganda.

66 Entrevista a Loris Romei (23-12-2014). 
sirve al Régimen, porque desde hace diez años asistimos a la misma película, aunque en la realidad ocurra otra cosa" 67 . Aunque la eficacia propagandística del noticiario no es demostrable, se producía un efecto contrario respecto a las intenciones: los espectadores rechazaban los mensajes de Luce. Así lo han señalado la mayoría de los entrevistados para esta investigación. El recuerdo del noticiario es negativo, porque se identificaba con el Régimen. Hay que tener en cuenta en las respuestas de los entrevistados que decir ahora que gustaba el noticiario $\mathrm{Lu}$ ce es políticamente incorrecto. Este motivo podría explicar el rechazo casi total de los noticiarios por parte de los entrevistados. Se responde en el contexto actual, después de muchos años de reflexión y crítica al fascismo, por lo que algunas respuestas pueden estar influidas por lo que se considera políticamente correcto en la actualidad.

El noticiario Luce se asocia con Mussolini. Es el gran protagonista. La mujer es la gran olvidada. En el recuerdo de los entrevistados sólo quedan las madres prolíficas o las Pequeñas Italianas, dos estereotipos femeninos creados por la propaganda del Régimen. De esto se deduce que la reiteración en los contenidos, hace mella en el público, quien, aunque rechace los mensajes, sin embargo, recuerda las imágenes más difundidas por el Régimen.

Aunque la propaganda del Régimen, la información sobre la guerra o las tendencias de la posguerra fueran difundidas por los noticiarios, en el recuerdo del público permanece más arraigado el cine de ficción con sus estereotipos y sus modas. El recuerdo de la guerra no es sólo el de Luce, sino el de las películas americanas vistas en los años cincuenta. La propaganda fascista fue más eficaz en el cine de ficción que en el informativo, como demuestran las respuestas de algunos entrevistados. La propaganda en los noticiarios era más evidente, y por tanto, su rechazo era mayor. En el cine de ficción, las ideas fascistas se ocultaban bajo las hazañas de héroes. Las estrellas del cine de ficción marcaban modas, estilos y comportamientos. En el cine de no ficción no hay estrellas, es más aséptico, al menos en apariencia. Por ello, su influencia tal vez va más dirigida a crear opinión sobre la marcha del propio país, sobre los enemigos, sobre determinadas cuestiones económicas, etc ${ }^{68}$.

En definitiva, el cine del fascismo dejó su huella en el público, tanto en forma de consenso como de rechazo. Junto a otros medios de comunicación, el cine, informativo y de ficción, fue un instrumento importante de la propaganda fascista $^{69}$. Aunque el recuerdo se haya diluido, el noticiario Luce es la información cinematográfica cuya influencia ha permanecido más tiempo. La identificación de Luce con el Régimen hace que la propaganda cinematográfica del noticiario sea menos eficaz, sobre todo cuando el público está predispuesto contra el fascismo, como es el caso de los entrevistados. Los modelos difundidos por el cine de ficción son los más arraigados en la sociedad del momento. La propaganda en películas de ficción puede ser más eficaz que la del cine informativo, más directo. Actores y actrices marcan modas. Películas que hacen soñar, mientras el público vive unos años de pan $d i$ legno e vin di nuvole ${ }^{70}$.

67 LONGANESI, Leo. "L'italiano", en Film italiano, n. 17-18, 1933 pp. 18-19.

68 BRUNETTA, Gian Piero. Historia del cinema italiano. Il cinema del regime (1929-1945), Roma, Editori Riuniti, 2001.

69 Cfr. CARABBA, Claudio. Il cinema del ventennio nero, Vallecchi, Florencia, 1974; REDI, Riccardo. Cinema italiano sotto il fascismo, Marsilio, Venecia, 1979, entre otros.

70 "Pan de madera y vino de nubes". 


\section{BIBLIOGRAFÍA}

ARGENTIERI, Mino. L'occhio del regime. Informazione e propaganda nel cinema del fascismo, Vallecchi, Florencia, 1979.

BERNAGOZZI, Giampaolo. Il mito dell'immagine. L'immagine del mito, Editrice Clueb, Bologna, 1983.

BRUNETTA, Gian Piero. Cinema italiano tra le due guerre, Mursia, Milán, 1975.

BRUNETTA, Gian Piero. La cinepresa e la storia: fascismo, antifascismo, guerra e resistenza nel cinema italiano. Bruno Mondadori, Milán, 1985.

BRUNETTA, Gian Piero. "La lunga marcia del cinema americano in Italia tra fascismo e guerra fredda". En ELLWOOD y BRUNETTA (Eds.), Hollywood in Europa, Einaudi, Bolonia, 1988.

BRUNETTA, Gian Piero. Historia del cinema italiano. Il cinema del regime (1929-1945), Editori Riuniti, Roma, 2001.

CARABBA, Claudio. Il cinema del ventennio nero, Vallecchi, Florencia, 1974; REDI, Riccardo. Cinema italiano sotto il fascismo, Marsilio, Venecia, 1979.

CARDILLO, Massimo. Il duce in moviola : politica e divismo nei cinegiornali e documentari "Luce", Dedalo, Bari, 1983.

CORONADO, Carlota. "Esposa y madre ejemplar: la maternidad en los noticiarios Luce durante el fascismo (1928-1945)", Historia y comunicación social, vol. 13 (2008), pp. 5-31.

CORONADO RUIZ, Carlota. "Mujeres en uniforme: las organizaciones fascistas femeninas en los noticiarios cinematográficos Luce (1928-1943)", Feminismos, vol. 1, n. 16 (2010), pp. 181-206.

DE GRAZIA Vittoria. Le donne nel regime fascista, Marsilio Editori, Venezia, 1993

DITTRICH-JOHANSEN, Helga. Le militi dell'idea. Storia delle organizacioni femminili del PNF, L. S. Olschki, Florencia, 2002).

FIELDING, Raymond. The American Newsreel 1911-1967, Norman, University Oklahoma Press, 1972.

HERRERA LEÓN, Fabián. "México y el Instituto Internacional de Cinematografía Educativa, 1927-1937", Estudios de historia moderna y contemporánea de México, vol. 1, n. 36 (2008), pp. 221-259.

HURET, Marcel. Ciné actualités: histoire de la presse filmée, 1895-1980, H. Veyrier, París, 1984.

LAURA, Ernesto G. Le stagioni dell'aquila. Storia dell'Istituto Luce, Ente dello Spettacolo, Roma, 2000.

LONGANESI, Leo. "L'italiano", en Film italiano, n. 17-18, 1933, pp. 18-19.

MELDINI, Piero. Sposa e madre esemplare. Ideologia e politica della famiglia durante il fascismo, Guaraldi
Editore, Rimini-Florencia, 1975.

MESSINA, Nunzia. Le donne del fascismo. Massaie rurali e dive del cinema nel Ventennio, Ellemme, Roma, 1987.

MONTERO, Julio; PAZ, María Antonia. Lo que el viento no se llevó: el cine en la memoria de los españoles (19311982), Ediciones Rialp, Madrid, 2011.

TRANCHE, Rafael R.; SÁNCHEZ-BIOSCA, Vicente y OTERO, José María. NO-DO: el tiempo y la memoria, Cátedra, Madrid, 2000.

TRANFAGLIA, Nicola; MURIALDI, Paolo y LEGNANI, Massimo. La stampa italiana nell'età fascista. Editori Laterza, 1980.

ZAGARRIO, Vito. Cinema e fascismo. Film, modelli, immaginari, Marsilio, Venecia, 2004. 